\title{
Investigation of an association between onset of narcolepsy and vaccination with pandemic influenza vaccine, Ireland April 2009-December 2010
}

D O’Flanagan (darina.oflanagan@hse.ie) ${ }^{1,2}$, A S Barret ${ }^{1,2}$, M Foley $^{1}$, S Cotter $^{1}$, C Bonner $^{3}$, C Crowe ${ }^{4}$, B Lynch ${ }^{5}$, B Sweeney ${ }^{6}$, H

Johnson 7 , B McCoy ${ }^{8}$, E Purcell 4

1. Health Service Executive, Health Protection Surveillance Centre, Dublin, Ireland

2. These authors contributed equally to this manuscript

3. Department of Health, Dublin, Ireland

4. Mater Private Hospital, Dublin, Ireland

5. Children's University Hospital Temple Street, Dublin, Ireland

6. Cork University Hospital, Cork, Ireland

7. Health Service Executive, Health Intelligence Unit, Dublin, Ireland

8. Our Lady's Children's Hospital, Crumlin, Dublin, Ireland

Citation style for this article:

O'Flanagan D, Barret AS, Foley M, Cotter S, Bonner C, Crowe C, Lynch B, Sweeney B, Johnson H, McCoy B, Purcell E. Investigation of an association between onset of narcolepsy and vaccination with pandemic influenza vaccine, Ireland April 2009-December 2010. Euro Surveill. 2014;19(17):pii=20789. Available online: http:// www.eurosurveillance.org/ViewArticle.aspx?Articleld=20789

Article submitted on 26 April 2013 / published on 01 May 2014

In 2011, the Irish Medicines Board received reports of onset of narcolepsy following vaccination against influenza $\mathrm{A}\left(\mathrm{H}_{1} \mathrm{~N}_{1}\right)$ pdmog with Pandemrix. A national steering committee was convened to examine the association between narcolepsy and pandemic vaccination. We conducted a retrospective populationbased cohort study. Narcolepsy cases with onset from 1 April 2009 to 31 December 2010 were identified through active case finding. Narcolepsy history was gathered from medical records. Pandemic vaccination status was obtained from vaccination databases. Two independent experts classified cases using the Brighton case definition. Date of onset was defined as date of first healthcare contact for narcolepsy symptoms. Incidence of narcolepsy in vaccinated and non-vaccinated individuals was compared. of 32 narcolepsy cases identified, 28 occurred in children/ adolescents and for 24 first healthcare contact was between April 2009 and December 2010. Narcolepsy incidence was 5.7 (95\% confidence interval (CI): 3.48.9) per 100,000 children/adolescents vaccinated with Pandemrix and 0.4 (95\% Cl: 0.1-1.0) per 100,000 unvaccinated children/adolescents (relative risk: 13.9; absolute attributable risk: 5.3 cases per 100,000 vaccinated children/adolescents). This study confirms the crude association between Pandemrix vaccination and narcolepsy as observed in Finland and Sweden. The vaccine is no longer in use in Ireland. Further studies are needed to explore the immunogenetic mechanism of narcolepsy.

\section{Introduction}

Narcolepsy is a sleep disorder characterised by excessive daytime sleepiness (EDS) and is often associated with cataplexy (episodic muscle weakness) triggered by emotion such as laughter or anger. Nocturnal sleep is usually fragmented and may be associated with sleep paralysis and hypnagogic hallucinations. Other symptoms may include weight gain and obesity, deterioration in school performance and emotional lability [1].

The precise aetiology of narcolepsy is unknown but it is generally considered to be triggered by a combination of genetic and environmental factors. An important predisposing genetic factor is a specific human leukocyte antigen (HLA), the HLA DQB1*0602. Patients with narcolepsy-cataplexy carry the allele $\mathrm{DQB1}{ }^{\star} 0602$ in $85-95 \%$ of cases, compared with about $30 \%$ of the general population [2]. Narcolepsy results from a decrease in levels of the neuropeptides hypocretin-1 and -2 . This loss is caused by destruction of the hypocretin-producing cells in the hypothalamus region in the brain. Narcolepsy diagnosis can be confirmed by hypocretin-1 (orexin-A) measurement in the cerebrospinal fluid (CSF). This test has a high sensitivity and specificity in patients with typical cataplexy [3]. In patients without cataplexy, the test of reference is the multiple sleep latency test (MSLT).

Possible environmental risk factors for narcolepsy include streptococcal infection and viral infections including influenza [4-6]. The prevalence of narcolepsy with cataplexy is estimated at 25-50 per 100,000 population in western industrialised countries. The incidence has been estimated at 0.74 cases per 100,000 person-years for narcolepsy with cataplexy and 1.37 for narcolepsy without cataplexy $[2,7]$. In most cases age at onset of symptoms is between 15 and 40 years. However, the disease often goes unrecognised and undiagnosed for many years, ranging from 1-61 years in a United Kingdom (UK) study [8]. 
In August 2010, the Swedish Medical Product Agency and the Finnish National Institute for Health and Welfare (THL) reported cases of narcolepsy as possible adverse events following vaccination against influenza $A\left(\mathrm{H}_{1} \mathrm{~N}_{1}\right)$ pdmog with Pandemrix $[9,10]$. By the end of March 2011, the Irish Medicines Board (the Irish pharmacovigilance authority) had also received reports of two confirmed cases of narcolepsy following vaccination with Pandemrix. In Ireland, two vaccine brands were used during the 2009-2010 pandemic influenza vaccination campaign: Pandemrix (GlaxoSmithKline) and Celvapan (Baxter). Celvapan was a whole-cell killed vaccine produced on a Vero cell line and did not contain any adjuvant. Pandemrix was an inactivated split influenza virus vaccine produced in eggs. It contained the adjuvant $\mathrm{ASO}_{3}$. Overall $88 \%$ of those receiving at least one dose of pandemic vaccine were vaccinated with Pandemrix and $12 \%$ with Celvapan. Both vaccines were used in the early phase of the pandemic vaccination programme when the at risk groups were prioritised to receive vaccine[11]. In the later phases, Pandemrix was mainly used when the vaccine was offered to children and adults outside of the main risk groups.

The objective of this study was to investigate if the risk of onset of narcolepsy was increased in the Irish population who received pandemic vaccine in comparison with those not receiving pandemic vaccine. The results of the investigation were presented in the final report of the National Narcolepsy Study Steering Committee in April 2012 [11]. The results reported here have been updated using the newly available 2011 census data (as opposed to 2006 census data in the final Department of Health report).

\section{Methods}

We conducted a retrospective population-based cohort study in order to investigate the association of narcolepsy with the pandemic vaccination in Ireland by comparing the incidence of narcolepsy in vaccinated and non-vaccinated individuals from 1 April 2009 to 31 December 2010.

\section{Study population}

Based on the preliminary signal of an increase in the incidence of narcolepsy in children and adolescents, three cohorts were defined: children aged 0-4 years, children/adolescents aged 5-19 years, and adults aged 20 years and over. However, no narcolepsy cases were reported in children aged 0-4 years in Ireland. Therefore the analysis was performed only for the two other cohorts, i.e. children/adolescents aged 5-19 years and adults. The 2011 census data by single year of age was used to estimate the number of the Irish population in each age group. We used similar age groups to studies conducted in other countries e.g. 4-19 year-olds in Finland [12], 4-18 year-olds in the United Kingdom [13], 4-19 year-olds in Norway [14] and 5-19 years in the Vaccine Adverse Event Surveillance \& Communication (VAESCO) study $[15,16]$.
Exposure to pandemic vaccination

In Ireland, the Health Service Executive (HSE) provided the pandemic vaccine to the population in several phases between November 2009 and March 2010. Those at highest risk of influenza and its complications received the vaccine in the early stages i.e. from 12 October 2009. Vaccination of healthy children aged less than 18 years started from 30 November 2009. Information on vaccination was collected in one of two databases, depending on where vaccination was administered: vaccination performed in general practitioner (GP) clinics were registered in the Primary care reimbursement service (PCRS) database and those in HSE mass vaccination clinics in the Pandemic data management system (PDMS) database. For each cohort, we extracted from the databases the number of individuals vaccinated with Pandemrix by week of vaccination. The number of unvaccinated individuals was computed by subtracting the number of individuals vaccinated with any pandemic vaccine brand from the total number of individuals reported in the 2011 census.

Case finding and ascertainment

Narcolepsy cases were identified through active case finding from April 2011 to October 2011 by contacting all sleep clinics, neurologists, paediatricians, GPs, psychiatrists, psychologists and public health nurses in Ireland. It was emphasised to investigating

\section{TABLE 1}

Brighton collaboration case definition for narcolepsy $[16,17]^{\mathrm{a}}$

\begin{tabular}{|c|c|}
\hline Level & Criteria \\
\hline Level 1 & $\begin{array}{l}\text { Excessive daytime sleepiness AND/OR } \\
\text { suspected cataplexy AND } \\
\text { CSF hypocretin-1 deficiency }\end{array}$ \\
\hline Level 2 & $\begin{array}{l}\text { Excessive daytime sleepiness AND } \\
\text { Definite cataplexy AND } \\
\text { Level } 1 \text { or } 2 \text { MLST abnormalities (mean sleep } \\
\text { latency } 8 \text { minutes for adults and } 12 \text { minutes for } \\
\text { children }<16 \text { years AND/OR } \\
\text { at least } 2 \text { sleep-onset REM periods) }\end{array}$ \\
\hline Level 3 & $\begin{array}{l}\text { Excessive daytime sleepiness AND } \\
\text { Level } 1 \text { MLST abnormalities (mean sleep latency }<8 \\
\text { minutes for adults and }<12 \text { minutes for children }<16 \\
\text { years AND } \\
\text { at least } 2 \text { sleep-onset REM period) }\end{array}$ \\
\hline All levels & In the absence of other mimicking disorders \\
\hline
\end{tabular}

CSF: cerebrospinal fluid; MLST: multiple sleep latency test.

a A Brighton Collaboration working group created a case classification to support the Vaccine Adverse Event Surveillance \& Communication (VAESCO) study. Although the final document had not been published the above draft criteria were utilised in the Irish study. 
neurologists and sleep clinics that cases should be reported regardless of exposure history. The various professional groups were individually contacted by mail and follow up was made by telephone contact with sleep clinics to confirm if no cases were observed. Two experts (one adult and one paediatric neurologist) reviewed the clinical history of narcolepsy cases in order to confirm the diagnosis and classify them using the internationally agreed Brighton Collaboration case definition for narcolepsy [17] (Table 1). The reviewers were blinded to the vaccination status of the cases. Neither of the independent experts were involved with the diagnosis or management of the cases included in the study. Cases were included in the study if (i) their date of first symptom of narcolepsy recorded in medical files occurred after 1 April 2009 and before 31 December 2010, (ii) cases or guardians gave oral informed consent, (iii) they were classified as level 1,2 or 3 as per the Brighton case definition. Prevalent cases with onset prior to April 2009 were excluded.

\section{Data collection}

Medical and narcolepsy history was collected from the medical records and clinical charts. Data included demographic information, details on history of narcolepsy, human leucocyte antigen (HLA) type, hypocretin-1 level and information on pandemic vaccination. For each narcolepsy case, we cross-checked the pandemic vaccination status, date of vaccination and vaccine brand in the PCRS and PDMS databases. CSF hypocretin-1 level values less than $50 \mathrm{pg} / \mathrm{ml}$ were considered as undetectable and highly suggestive of narcolepsy/cataplexy.

Estimation of the date of onset of narcolepsy

Because the date of onset of narcolepsy is often uncertain and date of diagnosis may be delayed, we used the date of first contact with healthcare for narcolepsy symptoms as retrieved from GP notes and clinical records to estimate the onset of narcolepsy. This date was considered as the most reliable and objective to estimate the onset of narcolepsy. Other dates were used in sensitivity analyses. The following dates were retrieved:

- Date of onset of first symptom of narcolepsy recalled by the patient or their parents (first documented history of symptoms such as excessive fatigue, sleep attacks, symptoms suggestive of cataplexy, etc.). When the exact date of symptom onset was unknown, it was approximated to the 15 of the reported month.

- Date of referral to a specialist for a sleep test.

- Date of MSLT which concluded the diagnosis of narcolepsy.

In the primary analysis, an incident case of narcolepsy was defined as having had a first contact with healthcare for narcolepsy symptoms during the study period. In the sensitivity analyses, we included cases with (i) date of onset, (ii) date of referral, (iii) date of
MLST within the study period (right-censored cases). In all analyses, an incident exposed case was defined as having received one or more dose of Pandemrix before the recalled date of first symptom of narcolepsy. Cases who had received the first dose of Pandemrix after the recalled symptom onset were considered as unvaccinated. The only narcolepsy case who had received Celvapan had the first contact with healthcare after 31 December 2010 and was therefore not included in the analysis of the risk of narcolepsy.

In Ireland, the suspected risk of narcolepsy associated with pandemic vaccination was not communicated to healthcare professionals and to the public before March 2011. Therefore we considered that individuals who consulted, were referred for a sleep test or diagnosed before this date were not associated with an increase in the awareness of professionals. As a proxy for the effect of media attention in the population, we also looked at trends in searches for the keyword 'narcolepsy' in Google Trends.

\section{Statistical analysis}

The primary follow-up time was defined from 1 April 2009 to 31 December 2010. Two further study periods were defined in the sensitivity analyses:

- Period 2 from 1 April 2009 to 15 August 2010, before the increased media attention that occurred in Sweden and Finland, respectively at the end of August 2010;

- Period 3 from 01 October 2009, after the pandemic vaccine became available in Ireland, up to 31 December 2010.

Cases were described according to their demographic and clinical characteristics. Bivariate analysis was conducted to compare the characteristics of Pandemrixvaccinated cases and unvaccinated cases. Differences were tested using Fisher exact test for categorical variables and Mann-Whitney test for quantitative variables.

The incidence of narcolepsy was calculated by dividing the number of cases by the follow-up time. The risk time (person-years) in Pandemrix-vaccinated individuals was calculated from the week of first vaccination until the end of the study period. The risk time in unvaccinated individuals was calculated from 1 April 2009 until the end of the study period for unvaccinated individuals, added to the time from 1 April 2009 to the week preceding vaccination for Pandemrix-vaccinated individuals.

In the sensitivity analyses of the risk of narcolepsy, we also used more specific case definitions: either cases with cataplexy or cases classified as level 1 in the Brighton case definition.

The relative risk (RR) was calculated as the ratio of the incidence rates for those vaccinated and unvaccinated, 
TABLE 2

Characteristics of narcolepsy cases by vaccination status, April 2009-December 2010, Ireland (n=32)

\begin{tabular}{|c|c|c|c|}
\hline Characteristics & $\begin{array}{c}\text { All cases }(\mathrm{N}=32) \\
n(\%)\end{array}$ & $\begin{array}{c}\text { Vaccinated cases }(\mathrm{N}=24)^{\mathrm{a}} \\
\mathrm{n}(\%)\end{array}$ & $\begin{array}{c}\text { Unvaccinated cases }(\mathrm{N}=7)^{\mathrm{a}} \\
\mathrm{n}(\%)\end{array}$ \\
\hline \multicolumn{4}{|l|}{ Age at disease onset } \\
\hline $5-9$ & $10(31)$ & $9(38)$ & $1(14)$ \\
\hline $10-14$ & $14(44)$ & $11(46)$ & $3(43)$ \\
\hline $15-19$ & $4(13)$ & $2(8)$ & $2(29)$ \\
\hline$\geq 20$ & $4(13)$ & $2(8)$ & $1(14)$ \\
\hline \multicolumn{4}{|l|}{ Sex } \\
\hline Male & $10(31)$ & $8(33)$ & $2(29)$ \\
\hline Female & $22(69)$ & $16(67)$ & $5(71)$ \\
\hline \multicolumn{4}{|l|}{ Brighton case definition } \\
\hline Level 1 & $15(47)$ & $14(58)$ & $1(14)$ \\
\hline Level 2 & $12(37)$ & $8(33)$ & $3(43)$ \\
\hline Level 3 & $5(16)$ & $2(8)$ & $3(43)$ \\
\hline \multicolumn{4}{|l|}{ Presence of cataplexy } \\
\hline Yes & $24(75)$ & $19(79)$ & $4(57)$ \\
\hline \multicolumn{4}{|l|}{ Time in days between onset of EDS and cataplexy } \\
\hline No. of cases with information & 19 & 16 & 2 \\
\hline Median & 62 & 62 & - \\
\hline Minimum-maximum & $0-365$ & $0-365$ & $76-243$ \\
\hline Q1-Q3 & $31-165$ & $31-142$ & - \\
\hline \multicolumn{4}{|l|}{ HLA typing } \\
\hline No. of test performed & 23 & 20 & 3 \\
\hline No. of cases with $\mathrm{DQB}_{1}{ }^{\star} 0602$ & 23 & 20 & 3 \\
\hline \multicolumn{4}{|l|}{ Hypocretin test } \\
\hline No. of tests performed & 19 & 17 & 2 \\
\hline No. with hypocretin-1 level values $<50 \mathrm{pg} / \mathrm{ml}$ & 18 & 17 & 1 \\
\hline
\end{tabular}

EDS: excessive daytime sleepiness; HLA: human leukocyte antigen; No: number; Q: quartile.

a One case vaccinated with Celvapan excluded in this analysis.

and the absolute attributable risk (AAR) was calculated as the difference in the incidence rates. We performed univariate Poisson regression using aggregated data in Stata version 11 to calculate the $95 \%$ confidence intervals $(\mathrm{Cl})$ around the RR. StatsDirect version 2.7.9 was used to compute the $95 \% \mathrm{Cl}$ around the AAR.

\section{Ethical approval}

The study protocol was reviewed and approved by the Faculty of Public Health Medicine Ethics Committee, Royal College of Physicians Ireland.

\section{Results}

The study cohorts comprised 906,280 children/adolescents and 3,325,643 adults.

Pandemic vaccination data

According to the PCRS and PDMS databases, 946,795 individuals received a first dose of Pandemrix between 12 October 2009 and 31 December 2010, a total of $88 \%$ of all first doses applied of pandemic vaccine. Pandemrix vaccine uptake was $20.8 \%$ across all age groups, $40.3 \%$ in those aged $0-4$ years, $37.8 \%$ in those aged $5^{-19}$ years, and $14.3 \%$ in those aged 20 years and over.
Description of narcolepsy cases

The active case finding identified 63 cases of narcolepsy. Of these, 25 cases had an onset of symptom prior to April 2009, one case did not agree to participate in the study and five cases did not meet the case definition. Thirty-two cases met the inclusion criteria and were included in the study.

Cases were predominantly reported from paediatric neurologists in Dublin and an individual specialist in sleep disorders with a particular interest in narcolepsy. Cases were referred to these centres from all over Ireland and there was no marked geographical clustering. All sleep clinics responded after telephone contact. There was a $100 \%$ concordance between the two evaluators when classifying the cases according to the Brighton Collaboration case definition. Based on the age at symptom onset, 28 of 32 cases were less than 20 years old and four cases were adults. Cataplexy occurred in all four adults and 20 of the 28 children/ adolescents. HLA typing was performed in 23 cases and all of them presented the HLA DQB1*0602 allele. Table 2 describes the characteristics of the 32 narcolepsy cases by vaccination status. 


\section{FIGURE 1}

Distribution of narcolepsy cases according to different estimated onset dates and by vaccination status, April 2009-December 2011, Ireland $(n=32)$

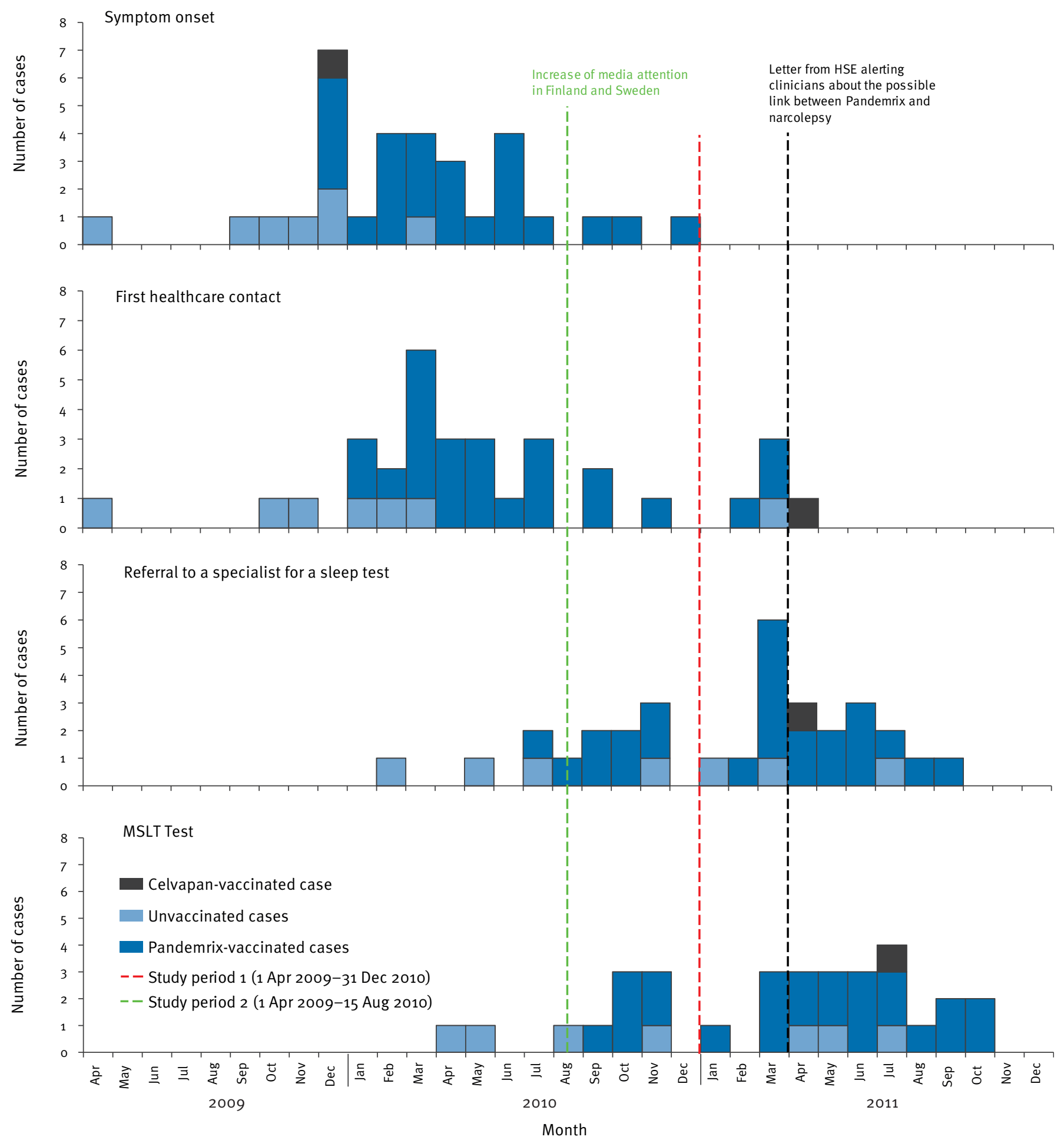

HSE: Health Service Executive; MLST: multiple sleep latency test.

Note: When the exact date of symptom onset was unknown, it was approximated to the 15 of the reported month. 


\section{TABLE 3}

Delay between vaccination against influenza A(H1N1)pdm09 with Pandemrix and symptom onset in vaccinated narcolepsy cases, Ireland, April 2009-December $2010(n=24)$

\begin{tabular}{|c|c|c|}
\hline Delay between vaccination and symptom onset & Number of cases & Cumulative proportion (\%) \\
\hline 0-6 days ( $(1$ week after vaccination) & 1 & $4.2 \%$ \\
\hline 7-27 days (1-3 weeks after vaccination) & 2 & $12.5 \%$ \\
\hline $28-55$ days (4-7 weeks after vaccination) & 5 & $33.3 \%$ \\
\hline $56-83$ days ( 8 to $<12$ weeks after vaccination) & 6 & $58.3 \%$ \\
\hline 3 months & 3 & $70.8 \%$ \\
\hline 4 months & 2 & $79.2 \%$ \\
\hline 6 months & 1 & $87.5 \%$ \\
\hline 7 months & 1 & $91.7 \%$ \\
\hline 8 months & 1 & $95.8 \%$ \\
\hline 9 months & 0 & $95.8 \%$ \\
\hline 10 months & 0 & $95.8 \%$ \\
\hline 11 months & 0 & $95.8 \%$ \\
\hline
\end{tabular}

The distribution of cases over time using different proxy dates for estimating the date of onset is presented in figure 1 , as well as the sensitivity analyses. Twenty-seven of 32 cases had their first contact with healthcare for narcolepsy symptoms within the primary study period.

The median delays between the recalled symptom onset and the first healthcare contact, the first referral to a specialist for a sleep test, and the date of MLST were 1.8 months (range o to 15.6 ), 12.7 months (range 3.0 to 17.5 ) and 12.7 months (range 3.9 to 19.3 ), respectively.

Of 32 cases, 24 had been vaccinated with Pandemrix before the recalled onset of the first narcolepsy symptom; five cases had received Pandemrix after the first symptom onset; one case had received Celvapan; two cases had never received any pandemic vaccine. All but one of the vaccinated cases had received one dose of vaccine. There was no association with any particular batch number and although nine cases had received a particular batch, it was the most common batch number reported in the PCRS and PDMS databases. For 24 vaccinated cases, the median delay between the vaccination and the first symptom of narcolepsy was $\mathbf{2 . 2}$ months (range 6 days to 12.8 months). The distribution of the delay between vaccination and symptom onset is shown in table 3 . The median delay between the vaccination and the first healthcare contact for narcolepsy symptom was 4.1 months (range 1.8 months to 16.0 months). Of 24 cases vaccinated prior to onset of symptoms, 20 were HLA-typed and all 20 cases presented the $\mathrm{DQB}_{1}{ }^{\star} 0602$ allele. The median age for these 20 was 11 years (range 5 to 17 ), seven were males and 13 females.
Comparison of Pandemrix-vaccinated and unvaccinated cases

Vaccinated cases $(n=24)$ and unvaccinated cases $(n=7)$ did not differ significantly in the age distribution (Fisher exact test, $p=0.36$ ) and male/female ratio (Fisher exact test, $p=1.0$ ). There was a significant difference in the levels of the Brighton Collaboration case definition, with vaccinated cases being more frequently classified as level 1 than unvaccinated cases ( $58 \%$ vs. $14 \%$, Fisher exact test $p=0.03)$. Cataplexy was more frequent in vaccinated than unvaccinated cases although the difference was not statistically different (79\% vs. $57 \%$, Fisher exact test $\mathrm{p}=0.33$ ).

\section{Risk of narcolepsy in children/adolescents}

The primary analysis included 24 narcolepsy cases with a first contact with healthcare because of narcolepsy symptom within the primary study period. Nineteen cases were vaccinated and five were unvaccinated. The incidence of narcolepsy during the primary follow-up time was 5.7 (95\% Cl: 3.4-8.9) per 100,000 person years in the vaccinated and 0.4 (95\% Cl: $0.1-1.0$ per 100,000 person years in the unvaccinated individuals. The RR was 13.9 (95\% Cl: 5.2-37.2) and the AAR associated with the vaccine was 5.3 narcolepsy cases per 100,000 vaccinated children/adolescents $(95 \% \mathrm{Cl}$ : 3.8-6.8). In sensitivity analyses using different periods and onset dates, the RR remained consistently greater than one. The lower limit of the $95 \% \mathrm{Cl}$ was greater than one in eight analyses and the lower limit below one in two analyses (Figure 2).

Considering only those cases presenting with cataplexy (14 vaccinated, 3 unvaccinated cases), the RR was 17.1 (95\% Cl: 4.9-59.4) in the primary analysis. Considering cases classified as level 1 in the Brighton case definition (13 vaccinated cases, 1 unvaccinated case), the RR was 47.5 (95\% Cl: 6.2-363.5) in the primary analysis. 
Sensitivity analysis for relative risk of narcolepsy in vaccinated ( $\mathrm{n}=22)$ compared with unvaccinated children and adolescents $(n=6)$ aged 5-19 years using different index dates and study periods, Ireland April 2009-December 2010

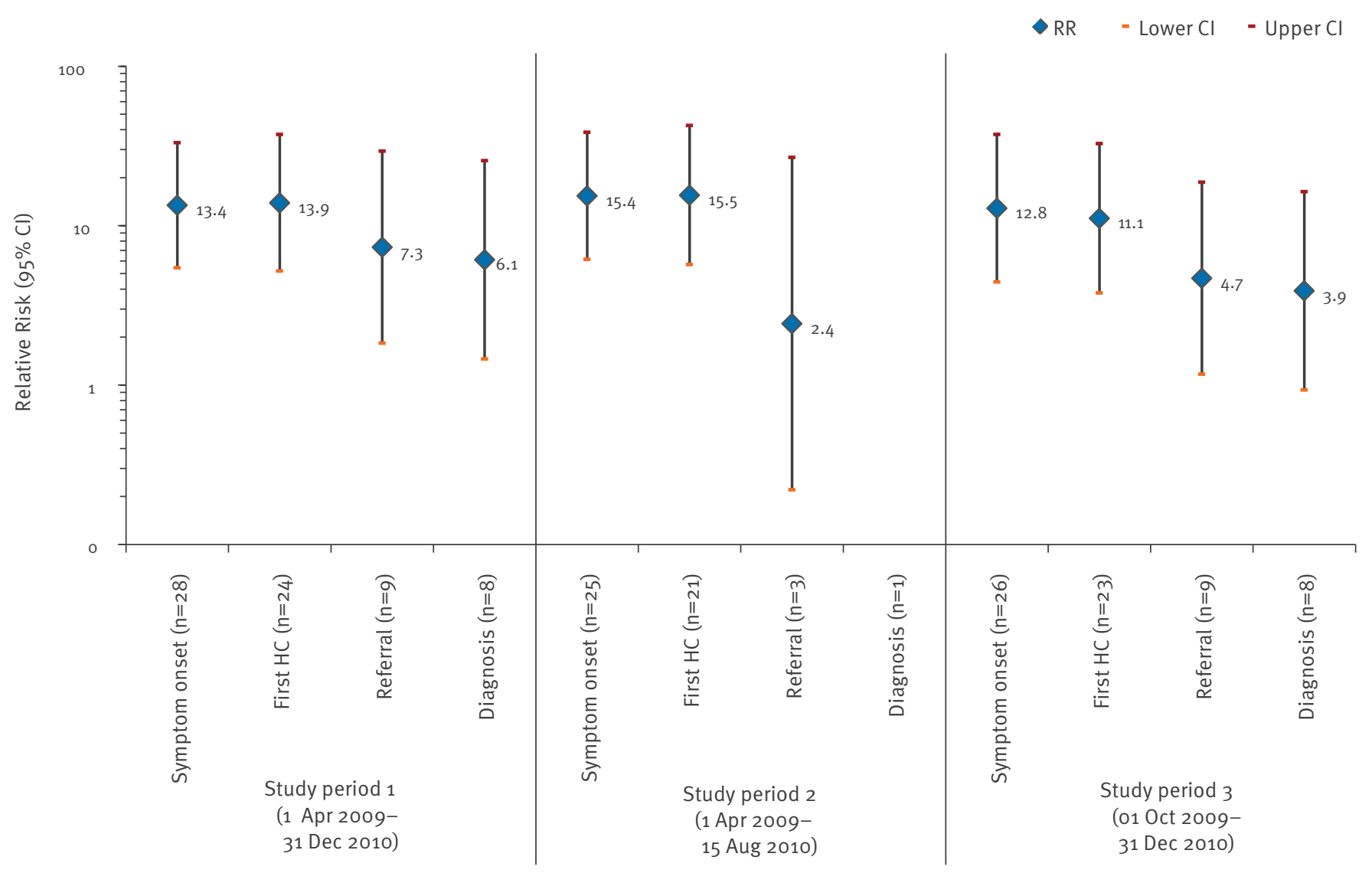

$\mathrm{Cl}$ : confidence interval; $\mathrm{HC}$ : healthcare contact; $\mathrm{RR}$ : relative risk.

\section{Risk of narcolepsy in adults}

The analysis included three adult narcolepsy cases with a first contact with healthcare because of narcolepsy symptom within the primary study period. Two cases were vaccinated with Pandemrix and one case was unvaccinated. The incidence of narcolepsy during the primary follow-up time was 0.39 ( $95 \% \mathrm{Cl}: 0.05-1.42)$ per 100,000 person years in the vaccinated adults and 0.02 (95\% Cl: $0.0005-0.11$ ) per 100,000 person-years in the unvaccinated adults. The RR was 20.4 (95\% Cl: 1.8-225.0) and the AAR associated with the vaccine was 0.37 narcolepsy cases per 100,000 vaccinated adults. Given the small number of cases in adults, the sensitivity analysis using different index dates or study periods could not be done. One adult case vaccinated with Celvapan was not included in the analysis.

\section{Media attention}

The trends in searches for the keyword 'narcolepsy' in Google suggested that concerns about narcolepsy in the Irish population started to rise in September 2011 as opposed to August 2010 in both Finland and Sweden (Figure 3).

\section{Discussion}

In Ireland, there is limited information on the epidemiology of narcolepsy. An Irish study conducted in 2009 estimated the prevalence of narcolepsy at five per 100,000 population. Most reported patients belonged to the age group of 13-19 year-olds. The estimate of prevalence based on this study was substantially less than the estimated prevalence rate reported in other western countries [7]. Although the authors did not rule out a low prevalence rate due to Irish unique ethnicity, they concluded that narcolepsy prevalence rates were largely underestimated possibly because of the misinterpretation of reported symptoms of EDS, the unclear care management of patients with suspected narcolepsy, the possibility of false negative sleep test results and the financial and logistical constraints of hypocretin-1 testing [18].

It is unlikely that this low prevalence is related to genetic non-susceptibility. A study of frequencies of HLA class I and II alleles and haplotypes of 250 Irish unrelated bone marrow donors found that the HLA $\mathrm{DQB}_{1}{ }^{*} 0602$ was present in $35 \%$ of them [19]. As there is no register for narcolepsy in Ireland it is impossible 


\section{FIGURE 3}

Google Trends searches for the keyword 'narcolepsy' in Finland, Ireland and Sweden, January 2005-August 2013
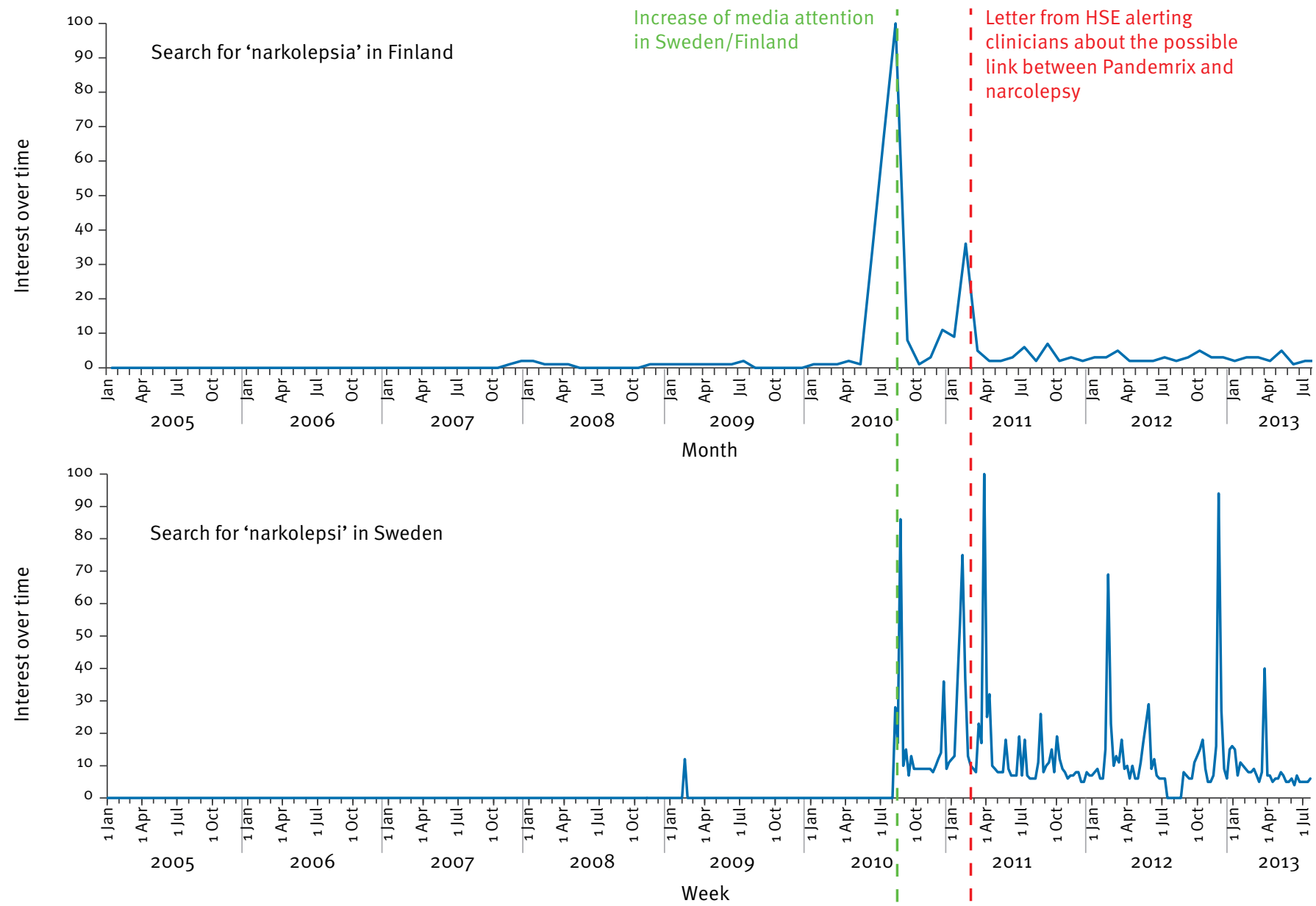

I

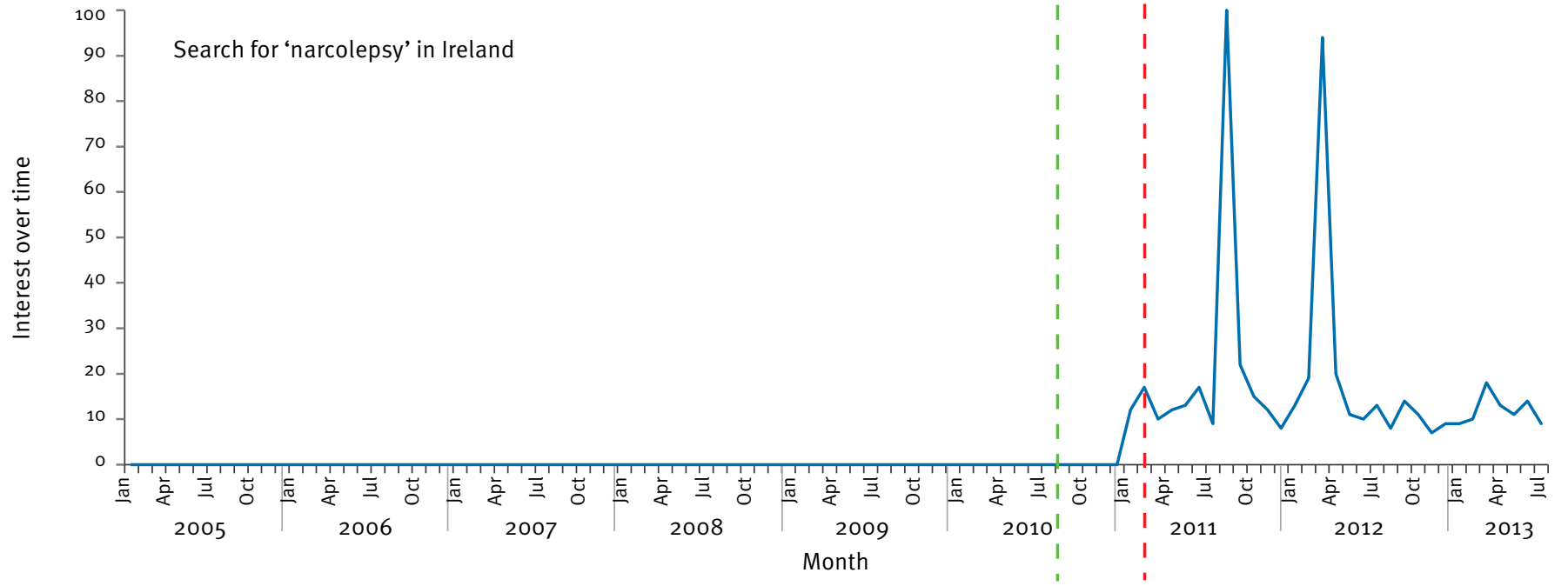

HSE: Health Service Executive.

Source: Google Trends - www.google.com/trends

Note from Google Trends: For queries that have low popularity, the breakdown is given by month, not week. In these cases, the monthly breakdown usually creates a smoother curve on the graph, making it easier to analyse any changes. 
to comment on the background incidence rates of narcolepsy prior to 2009.

Our study found a significant, 13.9-fold higher, risk of narcolepsy in children/adolescents vaccinated in Ireland with Pandemrix compared with unvaccinated children/adolescents. The absolute number of narcolepsy cases attributable to Pandemrix vaccination was five per 100,000 vaccinated children/adolescents or one in 19,000 vaccinated (95\% Cl: 1 in 15,000-1 in 26,000). These findings are remarkably similar to the results found in the retrospective population-based cohort study conducted in Finland in 2011 [12]. This study showed a 12.7 fold higher risk of developing narcolepsy in children/adolescents vaccinated with Pandemrix as compared with unvaccinated children/ adolescents. The vaccine attributable risk of developing narcolepsy was one in 16,000 vaccinated 4-19 year-olds ( $95 \% \mathrm{Cl}: 1$ in 13,000-1 in 21,000).

These vaccine attributable risks in Finland and Ireland are much higher than that recently reported in England where it was estimated as between one in 57,500 and one in 52,000 doses [13]. Miller et al. postulated that the lower attributable risk found in the UK may be related to a lower genetic susceptibility in England or because proportionately more vaccine was given in Finland and Ireland to adolescents, in whom incidence of narcolepsy is highest. Another possibility is that there remains underascertainment of narcolepsy cases in countries where there was neither active case finding nor widespread media coverage. It is likely that active case finding in Ireland led to improved detection and appropriate referral for diagnosis. Wijnans et al. reported on the incidence of narcolepsy in Europe before, during and after the influenza $A\left(\mathrm{H}_{1} \mathrm{~N}_{1}\right)$ pdmog pandemic and vaccination campaigns. The study used large linked databases in six countries in Europe [15]. Increases in incidence rates after the start of pandemic vaccination were detected in 5-19 year-olds in Denmark, Finland and Sweden but not in Italy, Netherlands, and the UK. Case verification was undertaken using data in the Dutch database and resulted in exclusion of $50 \%$ of initially identified cases in the Netherlands. The failure to detect the subsequently identified risk in the UK together with the verification problems identified in the Netherlands, indicates limitations to the sole use of large databases for the purpose of ruling out vaccine associated safety signals.

The primary study period in this study was chosen to include all cases with a possible exposure to both pandemic influenza infection and vaccination. However, when considering different index dates in the sensitivity analysis, excluding the cases that sought healthcare or were referred or had a MLST test after 31 December 2010, the RR remained consistently and significantly greater than one. We obtained similar results when restricting the study period to starting October 2009, when the pandemic vaccine had been made available to the Irish population.
The health-seeking behaviour, referral for a sleep test or numbers of cases diagnosed did not seem to have changed in Ireland following the increase of media attention in Finland. Looking at the earliest medical report dates of the cases of narcolepsy, we neither found an increase in healthcare-seeking behaviour, nor referral to specialists, nor diagnosis after August 2010. Whereas, a substantial number of cases were referred and diagnosed from March 2011 onwards. This coincided with communication to GPs in March 2011 by the Director of Health Protection, followed by communication to sleep clinics and paediatric and adult neurologists in April by the study investigators. As stated above, Google searches in Ireland suggest that concerns about narcolepsy in the Irish population started to rise in September 2011 as opposed to August 2010 in Finland and Sweden.

A source of potential bias in case selection may have been introduced by the use of active case finding in Ireland. Both GPs and hospital clinicians were made aware of the reason for the study. Clinicians were requested to investigate vaccinated and unvaccinated cases in a similar fashion. Although the case finding was performed irrespective of the cases' exposure status, it may be possible that vaccinated cases were more likely to have been identified. The RR based on the first contact with healthcare would become non-significant only if there were still an additional 36 unvaccinated cases to be diagnosed in the 5-19 year-olds in Ireland (RR: $1.70,95 \% \mathrm{Cl}: 0.98-2.92$ ). The RR point estimate would approach one only if there were still an additional 60 unvaccinated cases to be diagnosed in the 5-19 year-olds (RR:1.07, 95\% Cl: 0.6-1.8).

It is possible that GPs were more likely to refer vaccinated cases who had more subtle symptoms than those unvaccinated with subtle symptoms to specialists. However, we believe that GPs would refer those with severe symptoms of narcolepsy and cataplexy regardless of exposure history. If we include only children/ adolescents with severe symptoms such as cataplexy, the increased risk is still observed. Therefore, we think it is unlikely that the active case finding can account for the strong association with Pandemrix described in this study. In addition there is an ethical issue to be considered in investigation of rare potential side effects of vaccines or other medications. It is essential that affected children and adolescents are detected and referred for appropriate diagnosis and treatment. This creates a dilemma as it is also important to attribute causality with as little introduction of bias as possible. This dilemma is perhaps more marked with a disease that has an insidious onset as has narcolepsy. It is possible that excessive consideration of diagnostic bias accounts for the results of the primary analysis of the VAESCO study. In this study data from five European countries without a narcolepsy signal and with varying vaccination coverage in children and adolescents were pooled and it failed to find an association between the use of Pandemrix and onset of narcolepsy [16]. The 
same study confirmed the association in the 'signalling' countries Finland and Sweden. In the analysis the referral to MSLT was required to have happened before the initial media reports from Finland. This approach would have excluded all but one of the Irish cases from the analysis.

We identified very few narcolepsy cases in adults through our case finding and this limited the analysis of the risk of narcolepsy associated with pandemic vaccination. Although the RR point estimate for Pandemrix was relatively high, the wide $\mathrm{Cl}$ around the estimate impedes drawing any conclusion for adults. A significant association between pandemic vaccination and narcolepsy has been reported in adults in France [20]. A more recent study published from the Swedish Medical products agency reports an increased risk in those aged 21-30 years [21]. In May 2013, the THL in Finland also reported an increased risk of narcolepsy in young adults, although the risk was lower than that previously reported in children and adolescents [22].

It is interesting that the more recent data from Sweden has also noted an increase of diagnosed cases of narcolepsy in unvaccinated children and adolescents looking at data from October 2009 up to December 2011. Recent Norwegian studies have shown a decline in the incidence in vaccinated children aged $4^{-19}$ years in the second year after vaccination, falling to levels not significantly different from unvaccinated children during the same period [14]. Further work will be required to examine if that can be replicated in Ireland and elsewhere.

Because of the small number of cases, we had a very low power for testing the difference of characteristics between vaccinated and unvaccinated cases. Vaccinated cases were more likely to be classified as level 1 of the Brighton case definition and to present with cataplexy although this latter finding was not statistically significant. The delay between EDS onset and cataplexy onset was also shorter in vaccinated cases compared with unvaccinated cases, although not statistically significant. These results might suggest a clearer clinical picture of narcolepsy in vaccinated cases and a possible quicker development of symptoms as compared with the classical presentation.

In this study, we could not adjust the analysis for possible confounding factors such as previous infections or other vaccinations. In Ireland, children and adolescents were the group most affected during the 2009-2010 influenza $A\left(\mathrm{H}_{1} \mathrm{~N}_{1}\right)$ pandemic. In the 5-14 year-olds, the influenza-like illness incidence rate peaked in week 43 (starting 25 October 2009), i.e. one week before the pandemic influenza vaccination campaign was officially launched. The combination of pandemic influenza infection and vaccination might have initiated the development of narcolepsy. However, a serological study conducted in Finland does not support this hypothesis. In this study, only two of 45
Pandemrix-vaccinated narcolepsy patients showed specific antibody response against the NS1 protein from the influenza $A\left(\mathrm{H}_{1} \mathrm{~N}_{1}\right)$ pdmog virus [23]. Further studies are needed to explore other triggering factors and possible interactions.

It is noteworthy that a high number of cases in Ireland had the HLA allele DQB1*0602, all 23 tested were positive for this allele. The immunogenetic mechanism of narcolepsy and how Pandemrix vaccination contributed to its development need to be further studied and understood. While a number of European countries have now reported an increase in cases of narcolepsy associated with use of Pandemrix vaccine as yet there has been no report of an increase with the similar vaccine also produced by Glaxo Smith Kline, Arepanrix. Arepanrix also contains the adjuvant $\mathrm{ASO}_{3}$ and was used extensively in Canada. This could imply that it is not the adjuvant per se that accounts for the association with narcolepsy observed with the use of Pandemrix. Interestingly the European Centre for Disease Prevention and Control has pointed to differences in the manufacturing process for these two vaccines [24]. Further study of these differences may help to explain the pathogenic processes involved in the triggering of narcolepsy.

\section{Acknowledgements}

The authors would like to acknowledge Kirsty MacKenzie (HPSC), Paula Flanagan (HPSC), Margaret Fitzgerald (HPSC), Tara Kelly (HPSC), and Piaras O'Lorcain (HPSC) for their help in the investigation. We also acknowledge the assistance of colleagues in public health medicine departments in Ireland and the support from colleagues in Finland, Norway, Sweden and the ECDC.

\section{Conflict of interest}

None declared.

\section{Authors' contributions}

All authors contributed to the interpretation of the study, the revision of the draft manuscript and approved the final version. Darina O'Flanagan chaired the steering committee for the study, led the drafting of the manuscript and the original methodological design of the study. Anne-Sophie Barret conducted the data analysis and participated in drafting the manuscript. Margaret Foley conducted the collection and collation of the study data. Suzanne Cotter participated in the steering committee and provided the vaccine denominator data. Colette Bonner participated in the steering committee and agreed report and final paper. Catherine Crowe participated in the steering committee and provided much of the clinical data. The majority of the sleep studies were performed in her laboratory in conjunction with Dr Elaine Purcell. Bryan Lynch participated in the steering committee and in case identification, also in investigation and ongoing care of the majority of the children in the study. Brian Sweeney contributed the adult neurological perspective to the design and execution of the study. He also independently verified the cases of narcolepsy by applying the recommended criteria to each case. Howard Johnson contributed to the study design, data interpretation and drafting of the manuscript. 
Blathnaid McCoy conducted a blinded review of the clinical details of all cases to confirm diagnosis and classify according to established criteria. Elaine Purcell participated in the steering committee and provided much of the clinical data. The majority of the sleep studies were performed in her laboratory in conjunction with $\mathrm{Dr}$ Catherine Crowe.

\section{References}

1. Bozorg AM, Benbadis SR, Thomas DJ. Narcolepsy clinical presentation. Updated 29 Jul 2013. New York, NY: Medscape; 2013. Available from: http://emedicine.medscape.com/ article/1188433-clinical

2. Overeem S, Black JL,3rd, Lammers GJ. Narcolepsy: immunological aspects. Sleep Med Rev. 2008 ;12(2):95-107. http://dx.doi.org/10.1016/j.smrv.2007.07.010

3. Mignot E, Lammers GJ, Ripley B, Okun M, Nevsimalova S, Overeem $S$, et al. The role of cerebrospinal fluid hypocretin measurement in the diagnosis of narcolepsy and other hypersomnias. Arch Neurol. 2002;59(10):1553-62.4.

4. Longstreth WT Jr, Ton TG, Koepsell TD. Narcolepsy and streptococcal infections. Sleep. 2009;32(12):1548.

5. Han F, Lin L, Warby SC, Faraco J, Li J, Dong SX, et al. Narcolepsy onset is seasonal and increased following the $2009 \mathrm{H}_{1} \mathrm{~N}_{1}$ pandemic in China. Ann Neurol. 2011;70(3):410-7. http://dx.doi. org/10.1002/ana.22587

6. Aran A, Lin L, Nevsimalova S, Plazzi G, Hong SC, Weiner K, Zeitzer J, Mignot E. Elevated anti-streptococcal antibodies in patients with recent narcolepsy onset. Sleep. 2009;32(8):97983. 7 Longstreth WT Jr, Koepsell TD, Ton TG, Hendrickson $A F$, van Belle G. The epidemiology of narcolepsy. Sleep 2007;30(1):13-26.

7. Longstreth WT Jr, Koepsell TD, Ton TG, Hendrickson $A F$, van Belle G. The epidemiology of narcolepsy. Sleep 2007;30(1):13-26.

8. Morrish E, King MA, Smith IE, Shneerson JM. Factors associated with a delay in the diagnosis of narcolepsy. Sleep Med. 2004;5(1):37-41. http://dx.doi.org/10.1016/j. sleep.2003.06.002

9. Medical Products Agency (MPA). The MPA investigates reports of narcolepsy in patients vaccinated with Pandemrix. Updated 18 Aug 2010. Uppsala: MPA; 2010. Available from: http:// www.lakemedelsverket.se/english/All-news/NYHETER-2010/ The-MPA-investigates-reports-of-narcolepsy-in-patientsvaccinated-with-Pandemrix/

10. National Institute for Health and Welfare (THL). National Institute for Health and Welfare recommends discontinuation of Pandemrix vaccinations. Updated 25 Aug 2010. Helsinki: THL; Aug 2010. Available from : http://www.thl.fi/en_US/web/ en/pressrelease? $\mathrm{id}=\mathbf{2 2 9 3 0}$

11. National Narcolepsy Study Steering Committee. Investigation of an increase in the incidence of narcolepsy in children and adolescents in 2009 and 2010. [Accessed on $8 \mathrm{Apr}$ 2013] Dublin: Department of Health. Available from: http:// www.dohc.ie/publications/pdf/Final_Report_of_National_ Narcolepsy_Study_Steering_Committee.pdf?direct=1

12. Nohynek H, Jokinen J, Partinen M, Vaarala O, Kirjavainen T Sundman J, et al. $\mathrm{ASO}_{3}$ adjuvanted $\mathrm{AH}_{1} \mathrm{~N}_{1}$ vaccine associated with an abrupt increase in the incidence of childhood narcolepsy in Finland. PLoS One. 2012;7(3):e33536. http:// dx.doi.org/10.1371/journal.pone.0033536

13. Miller E, Andrews N, Stellitano L, Stowe J, Winstone AM, Shneerson J, Verity C. Risk of narcolepsy in children and young people receiving $\mathrm{ASO}_{3}$ adjuvanted pandemic $\mathrm{A} / \mathrm{H}_{1} \mathrm{~N}_{1} 2009$ influenza vaccine: retrospective analysis. BMJ. 2013;346:f794. http://dx.doi.org/10.1136/bmj.f794

14. Heier MS, Gautvik KM, Wannag E, Bronder KH, Midtlyng E, Kamaleri Y, Storsaeter J. Incidence of narcolepsy in Norwegian children and adolescents after vaccination against $\mathrm{H}_{1} \mathrm{~N}_{1}$ influenza A. Sleep Med.2013;14(9): 867-71. http://dx.doi. org/10.1016/j.sleep.2013.03.020

15. Wijnans L, Lecomte C, de Vries C, Weibel D, Sammon C, Hviid A, et al. The incidence of narcolepsy in Europe: before, during, and after the influenza $A\left(\mathrm{H}_{1} \mathrm{~N}_{1}\right)$ pdmog pandemic and vaccination campaigns. Vaccine. 2013;31(8):1246-54. http:// dx.doi.org/10.1016/j.vaccine.2012.12.015

16. European Centre for Disease Prevention and Control (ECDC). Narcolepsy in association with pandemic influenza vaccination (a multi-country European epidemiological investigation). Stockholm: ECDC; Sep 2012. Available from: http://vaesco. net/vaesco/results/main/o4/text_files/file/ECDC\%202012\%20 VAESCO $\% 20$ Narco\%2oreport\%20FULL.pdf
17. Poli F, Overeem S, Lammers GJ, Plazzi G, Lecendreux M, Bassetti CL, et al. Narcolepsy as an adverse event following immunization: case definition and guidelines for data collection, analysis and presentation. Vaccine. 2013;31(6):9941007.

http://dx.doi.org/10.1016/j.vaccine.2012.12.014

18. Doherty L, Crowe C, Sweeney B. National narcolepsy survey. Ir Med J. 2010;103(4):110, 112-3.

19. Dunne C, Crowley J, Hagan R, Rooney G, Lawlor E. HLA-A, $\mathrm{B}, \mathrm{CW}, \mathrm{DRB} 1, \mathrm{DQB} 1$ and DPB1 alleles and haplotypes in the genetically homogenous Irish population. Int Immunogenet. 2008;35(4-5):295-302. http://dx.doi. org/10.1111/j.1744-313X.2008.00779.x

20. Service de pharmacologie (INSERM CIC-P 0005 PharmacoEpidémiologie), Université Bordeaux Segalen - CHU de Bordeaux. Etude NarcoFlu-VF (NarcoFlu VAESCO-France): Grippe, vaccination antigrippale et narcolepsie : contribution française à l'étude cas-témoins européenne. [Flu, influenza vaccination and narcolepsy: French contribution to the European case-control study.]. Version 2.0 of 6 Aug 2012. Bordeaux: Université de Bordeaux; Sep 2012. French. Available from: http://ansm.sante.fr/content/download/43562/566132/ version/1/file/pi-120920-Etude+NarcoFlu-VF.pdf

21. Medical Products Agency (MPA). Registry study confirms increased risk of narcolepsy after vaccination with Pandemrix in children and adolescents and shows an increased risk in young adults. Updated 26 Mar 2013. Uppsala: MPA; Mar 2013. Available from: http://www. lakemedelsverket.se/english/All-news/NYHETER-2013/ Registry-study-confirms-increased-risk-of-narcolepsy-aftervaccination-with-Pandemrix-in-children-and-adolescents-andshows-an-increased-risk-in-young-adults/

22. National Institute for Health and Welfare (THL). Increased risk of narcolepsy observed also among adults vaccinated with Pandemrix in Finland. Updated 23 May 2013. Helsinki: THL; May 2013. Available from: http://www.thl.fi/en_US/web/en/ pressrelease? $\mathrm{id}=33516$

23. Melén K, Partinen $M$, Tynell J, Sillanpää $M$, Himanen SL, Saarenpää-Heikkilä 0 , et al. No serological evidence of influenza A H1N1pdmog virus infection as a contributing factor in childhood narcolepsy after Pandemrix vaccination campaign in Finland. PLoS One. 2013;8(8): e68402. http://dx.doi. org/10.1371/journal.pone.0068402

24. European Centre for Disease Prevention and Control (ECDC). Scientific advances. Association of receipt of Pandemrix ${ }^{\mathrm{TM}}$ and narcolepsy in children and adolescents in the UK (England). Stockholm: ECDC; Mar 2013. Available from: http://ecdc.europa.eu/en/ activities/sciadvice/_layouts/forms/Review_DispForm. aspx? List $=$ a3216f4c-fo $40-4 f_{51-9 f} 77-$ a96046 dbfd $72 \& I D=735$ 